\title{
STRESS, STRESSORS AND COPING STRATEGIES AMONG UNIVERSITY NURSING STUDENTS
}

\author{
Retneswari Masilamani ${ }^{1,2}$, Myat Moe Thwe Aung ${ }^{3}$, Hamidah Othman ${ }^{3}$, Aini Abu Bakar ${ }^{1}$, Tan Chung Keat ${ }^{1}$ \\ Sugapriyan Ravichandran ${ }^{4}$, Lim Kit Wing ${ }^{1}$, Chuah Wei Hong ${ }^{1}$, Lim Kok Hong ${ }^{1}$, Ng Elson ${ }^{1}$, Tan Jef Wayna ${ }^{1}$, \\ Vickneshan Selvathurai ${ }^{1}$, Tan Ze Xuan ${ }^{1}$ and Surein Prasad Jagajarantan ${ }^{1}$
}

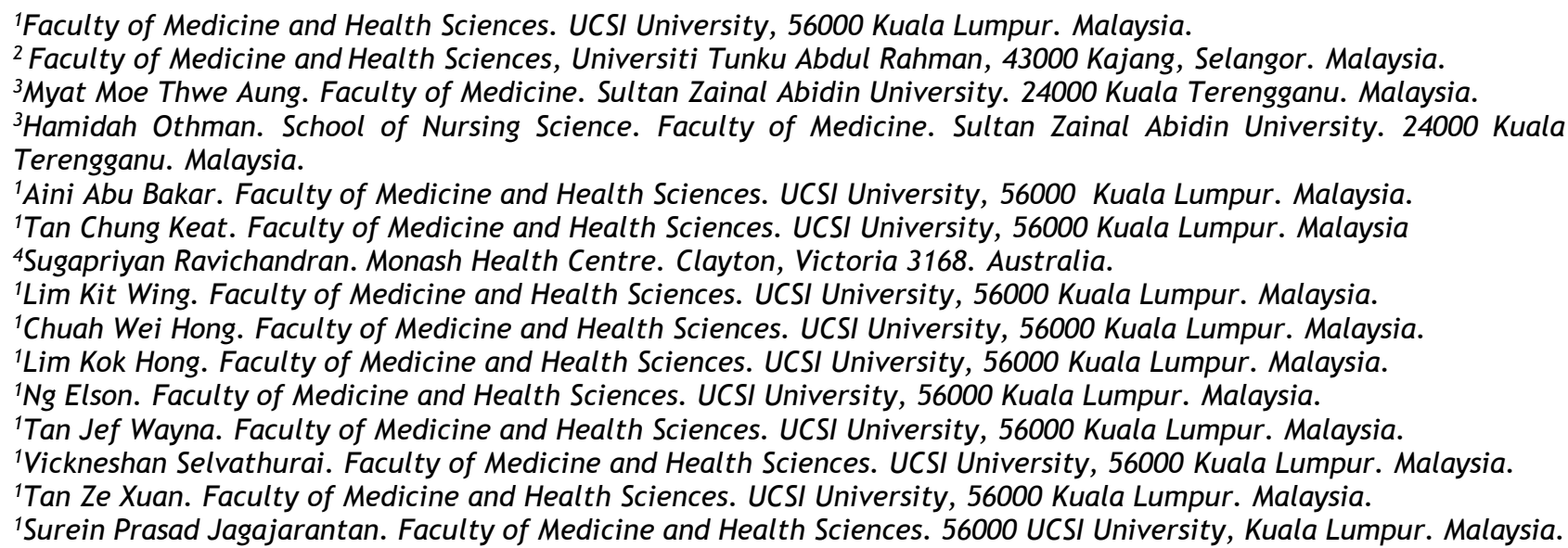

Corresponding Author: Retneswari Masilamani

Email: retnes@gmail.com

\begin{abstract}
Literature has documented that student nurses undergo stress in their academic and clinical setting. This raises concerns because stress during undergraduate training may result in psychological or emotional impairment during the nurses' professional life and ultimately affect the quality of patient care. The Objective of the study was to study the prevalence of stress, and the association between sociodemographic factors, stressors and coping strategies with stress. This was a cross-sectional study on 96-year 1-3 nursing students from a government university done between 2015-2018. Bahasa Malaysia translated The General Health Questionnaire, Stressors in Nursing Student Scale Questionnaire and Brief COPE Questionnaire was used in this study. This study had Malay (95.9\%) and female (91.7\%) dominated population. The prevalence of stress in student nurses was $25 \%$. No association was reported between sociodemographic factors and stress. Among the 4 stressors educational, clinical, confidence and financial, clinical stressor scored the highest mean 6.40 (SD \pm 3.66$)$. Confidence stressor ( $A O R=1.2695 \% \mathrm{Cl} 1.04-1.53)$ was the only stressor associated with stress. The top 3 coping strategies practiced by the student nurses were religion (praying), acceptance and planning. Self-blame (AOR $8.1895 \% \mathrm{Cl}$ 1.86-35.91) was the only coping strategy associated with stress. Stress management programmes, and workshops on stress and coping strategies should be conducted yearly to ensure a wellbalanced environment for good learning experiences and prevent stress related health problems and improved academic performance.
\end{abstract}

Keywords: student nurses, student nurse stress, stress, stressors, coping strategies, university student nurses.

\section{INTRODUCTION}

There is an increasing body of evidence relating to stress among nursing students. This raises concerns because stress during undergraduate training may result in psychological or emotional impairment during the nurses' professional life and ultimately affect the quality of patient care ${ }^{1-}$ 3 . Nursing being a performance-based profession, theory and clinical learning environments contribute extensively in the acquisition of professional abilities and enables the nursing students to enter the nursing profession and render services competently as required by a registered nurse ${ }^{4}$.
Literature review revealed that nursing students globally experience stress ${ }^{5-10}$. Beck revealed that nursing students experience higher levels of stress and more physical and psychological symptoms when compared to students from other healthrelated disciplines ${ }^{6}$. Multiple studies demonstrated a consistent high level of stress experienced by student nurses during various stages of their course, ranging from $33.7 \%$ to $97 \%^{11-14}$. The consequences of unchecked stress among nursing students may include poor professional image resulting in attrition of new recruits to nursing, dropout of distressed students who may not complete the programme successfully and poor performance outcomes ${ }^{15}$ 
People develop routine ways of dealing with stress and these styles or coping strategies can influence their reactions ${ }^{16}$. It has been reported that coping strategies also depended on experience ${ }^{17}$. Experienced workers using problem-focused ways of coping, whilst students and leavers depended on emotion-focused strategies to deal with stressful situations. Such disparity in coping strategies were shown to be related to personality characteristics of the stressful episode. On the contrary, it has been found the student tend to use a mixture of both problem based and emotion focused methods of coping ${ }^{18}$.

In Malaysia, despite the adverse impact of stress among nursing students, there remains a dearth of local study into the aforementioned issues. Such a study is needed to assess the prevalence of stress among nursing students. This will enable student nurses to identify the type of stressors and enhance the level of awareness among themselves on stress levels and type of stressors encountered. It will further enable them to identify proper coping strategies to mitigate the sources of stress and stressors in a positive way. As nursing students will be registered and qualified to deliver healthcare service to the sick and poor in future, nursing educators must recognize this problem early to help them cope with these stressors, avoid negative coping practices such as drug-abuse, and avert stress conditions to progress leading to exhaustion, burnout, and in extreme cases, suicide.

There is to date only one study published on stress among nurse students from Ministry of Health, Malaysia, reporting only descriptive findings in a north-eastern part of the country. Thus, the outcome of this study will not only provide strength to previous findings but add to the coping mechanisms reported by undergraduate nursing students in an academic institution. The Objectives of the study are to: 1 . Study the prevalence of stress, stressors, coping strategies among nursing students and 2. Identify the sociodemographic stressors and coping predictors associated with stress.

\section{METHODOLOGY}

This was a cross-sectional study on year 1-3 nursing students from a government university in the Northern Eastern State of Malaysia. The study subjects were 124 nursing students where only 96 nurses participated as 19 students posted in district hospitals were left out due to logistic constraints and another 9 students were absent on day of data collection. Based on StasCalc Epi Info 7 with an accepted margin of error of $\pm 5 \%$, a confidence level of $95 \%$, ensuring a power of $80 \%$ and an expected frequency of $30 \%$, for a population of 124 nursing students in this university, the sample size was calculated as 94 . Ninety six out of 124 nursing students participated in this study. The study was carried out between
2015 till 2018. The inclusion criteria were all the registered university nursing students and those who provided informed consent. Exclusion criteria were those who refused to provide consent, were absent and had known mental disorders. The independent variables sociodemographic profile (age, gender, ethnicity, year of study, source of tuition fee, perception of financial status), stressors and coping strategies. The outcome was stress.

A self-administered question comprising of sociodemographic profile, 43 item Stressors in Nursing Students Scale (SINS), General Health Questionnaire 12 items (GHQ 12), and 28 items Brief Coping Inventory were used in this study ${ }^{19-21}$. The GHQ 12 item is a validated and reliable questionnaire in Bahasa Malaysia (BM) with good psychometric properties ${ }^{22,}{ }^{23}$. The GHQ was used to measure the stress levels on a likert scale of 1 4. The SINS questionnaire had 4 subscales namely; clinical, confidence, education and finance with each item to be answered on a likert scale ranging from $1=$ not stressful at all to $5=$ extremely stressful. The 28 item Brief COPE Inventory measures a broad range of coping response requiring respondents to answer on a 4-point scale from 'I usually don't do this at all' to 'I usually do this a lot'. The 28 items are further grouped into 14 domains of coping - self-distraction, active coping, denial, substance use, use of emotional support, behavioral disengagement, venting, use of instrumental support, positive reframing, selfblame, planning, humour, acceptance and religion. The SINS and Brief Coping Inventory were subjected to forward backward translation by bilingually competent lecturers and medical students, and through several discussions, a final $B M$ version of the SINS and Brief COPE Inventory were finalized. The original English version of the SINS and Brief Coping Inventory have reported good psychometric properties ${ }^{20}$, 24 .The Cronbach's alpha reported for the current study for GHQ 12 items was 0.80 , SINS ranged from 0.88 to 0.96 (4 components of the SINS questionnaire) and Brief COPE Inventory was 0.89 .

Pretesting of all questionnaires were carried out for face validity among groups of medical students and pilot study to test internal consistency was conducted on a group of nurse students who were not involved in the final study. Data was collected in a classroom from the year 1 to year 3 diploma nursing students after distributing the information sheet followed by a briefing on the study details. Written consent was obtained from all study respondents coupled with verbal reassurance that participation was entirely voluntary and that participants could withdraw at any time. Data collected were stored in a manner compliant with data-protection. Ethical clearance was obtained from the Medical Research Ethics Committee in UCSI University and permission to conduct the study among nursing students was obtained from the Dean of the concerned university. 
Data Analysis

SPSS version 20 was used as software for data analysis. Once all data were entered, a number of standard checks for accuracy, incomplete and inconsistent data were done to ensure dataset was clean. Descriptive statistical analysis was performed by using frequencies, percentages and means on all variables studied accordingly.
Logistic regression was carried out to study association between stress and sociodemographic characteristics, stressors and coping strategies. All hypotheses tests were two-sided and the level of significance $\alpha$ was set at 0.05 . The confidence level was set at $95 \%$.

\section{RESULTS}

A total of 96 student nurses out of 124 participated in the study providing a response rate of $77.4 \%$.

Table 1: Sociodemographic characteristics of the respondents $(n=96)$

\begin{tabular}{lcc}
\hline Variables & Mean (SD) & Frequency (\%) \\
\hline Age in years & $20.2(0.90)$ \\
Gender & \\
Male & $8(8.3)$ \\
Female & $88(91.7)$ \\
Ethnicity & \\
Malay & $92(95.9)$ \\
Chinese & $1(1.0)$ \\
Others & $3(3.1)$ \\
Year of study & $21(21.9)$ \\
Year 1 & $36(37.5)$ \\
Year 2 & $39(40.6)$ \\
Year 3 & \\
Perception of financial status & \\
Not enough for tuition fee & $6(6.3)$ \\
Not enough for personal expenses & $45(46.9)$ \\
Sufficient (Able to afford all expenses) & $44(45.8)$ \\
Comfortable (Have more than enough money) & $1(1.0)$ \\
Parent's marital status & $83(86.5)$ \\
Married & $5(5.2)$ \\
Divorce & $8(8.3)$ \\
Parental loss & & $8(8.3)$ \\
Frequency of exercise & $74(77.1)$ \\
Never & $8(8.3)$ \\
sometimes ( less than 3 times a week ) & $6(6.3)$ \\
often ( 3 times or more a week ) & \\
always ( 5 times or more a week ) & \\
\hline
\end{tabular}

Table 1 describes the mean age of the respondents as 20.2 (SD - 0.90), ranging from 1924 years of age. Majority were females (91.7\%) and Malays (95.9\%). All students in this university receive study loans (source of tuition fee) from The National Higher Education Fund Corporation, a government institution that offers study loans specifically for tertiary education for Malaysian students. There were no Indian students in this study. More than $3 / 4$ of the respondents reported exercising sometimes for less than 3 times a week.
Based on the GHQ 12 item questionnaire where a score of 4 or more classifies a respondent as stressed, generated a prevalence of $25 \%$ stress among the nursing students.

Logistic regression did not report significant association between any of the sociodemographic characteristics (age, gender, ethnicity, year of study, perception of financial status, parent's marital status, frequency of exercise, and stress among the respondents. Table 2 shows clinical stressors to be the highest ranked and lowest being financial stressors. 
Table 2: Rating of the Stressors in the Stress in Nursing Student Scale

\begin{tabular}{llc}
\hline Variables & Mean (SD) & Ranking \\
\hline Educational stressors & $5.18(2.51)$ & 3 \\
Clinical stressors & $6.40(3.66)$ & 1 \\
Confidence stressors & $5.98(3.83)$ & 2 \\
Financial stressors & $3.06(2.07)$ & 4 \\
\hline
\end{tabular}

Table 3: Multivariable analysis of the association between the stressors with stress

\begin{tabular}{lcccc}
\hline \multicolumn{1}{c}{ Variable } & $\begin{array}{c}\text { Crude } \text { OR }^{a} \\
(95 \% \mathrm{Cl})\end{array}$ & $\begin{array}{c}\text { Adjusted } O R^{b} \\
(95 \% \mathrm{Cl})\end{array}$ & Wald Statistics $^{b}(\mathrm{df})$ & $\begin{array}{c}P \\
\text { Value }^{\mathrm{b}}\end{array}$ \\
\hline $\begin{array}{l}\text { Confidence } \\
\text { stressors }\end{array}$ & $1.40(1.19,1.65)$ & $1.26(1.04,1.53)$ & $5.36(1)$ & 0.021 \\
\hline
\end{tabular}

aSimple logistic regression, ${ }^{b}$ Multiple logistic regression (Backward LR method was applied). The model reasonably fits well. Model assumptions are met.

Univariable logistic regression analysis between the 4 stressors clinical, confidence, education and financial reported all these stressors to be associated with stress. Multivariable logistic regression showed only the confidence stressor to be associated with stress (Table 3 ). The top 3 ranked coping strategies practiced among the respondents was religion $(87.5 \%)$, followed by acceptance (82.3\%) and planning (76\%). The least practiced coping strategy practiced was substance use $(5.2 \%)$.

Table 4 shows univariate analysis to test association between coping strategies and stress. Out of 14 coping strategies, only self-blame had significant association with stress $(p=0.005)$. Table 5 shows multivariable analysis to test the association between coping strategies and stress. Out of 14 coping strategies, only self-blame showed significant association with stress $(p=$ 0.005).

\section{DISCUSSION}

In this study, the prevalence of stress among the nursing students was $25 \%$. Comparing prevalence of stress among nurses is difficult as methodologies, different types of instruments, cultural and academic environment or curricula may differ ${ }^{25}$. However common use of the GHQ 12 items questionnaire in assessing the stress levels allows comparisons to be made, where the prevalence among the National Health Services
(NHS) nurses was reported to range between $27 \%$ - $29 \%$ while prevalence among senior doctors was $47 \% 26,27$. Another study done in UK showed a prevalence of nursing student stress as $33.7 \%$ overall. This broke down into $36.5 \%$ for degree students and $33.5 \%$ for diploma students ${ }^{14}$. The results of the 2017 NHS staff survey, published in March 2018 revealed the proportion of staff who were unwell because of work related stress in the past 12 months had increased to $38.4 \%$, from $36.7 \%$ in $2016^{28}$. Among the few studies done in Malaysia, stress in general among university students was reported as $23.7 \%^{29}$ while students studying in medicine and health sciences reported the highest mean stress score of 1051.8 with standard deviation of 342.29 compared to students from other faculties ${ }^{30}$. Studies from Jordan, Punjab and Brazil reported stress levels of $52.9 \%, 69.2 \%$ and $91.9 \% 11,31,32$. This showed that the stress levels reported in the current study among nurses and other Malaysian students was lower than those reported overseas. This could be explained by reasons as stated above and more to cultural differences.

There were not significantly associated sociodemographic factors with stress reported in this study. Similar findings were reported by a study done among Australian student nurses ${ }^{33}$. There were other studies which showed significant association between year of study and another both age and year of study with nursing student stress ${ }^{34-36}$. 
Table 4: Simple Logistic Regression analysis between coping strategies and stress

\begin{tabular}{|c|c|c|c|}
\hline Variables & $\begin{array}{l}\text { Crude OR } \\
(95 \% \mathrm{Cl})\end{array}$ & $\begin{array}{c}\text { Wald statistics } \\
\text { (df) }\end{array}$ & $P$ value \\
\hline \multicolumn{4}{|l|}{ Self-distraction } \\
\hline Practiced & $1.06(0.40,2.83)$ & $0.02(1)$ & 0.901 \\
\hline Not practiced & 1.00 & & \\
\hline \multicolumn{4}{|l|}{ Active coping } \\
\hline Practiced & $1.00(0.36,2.76)$ & $0.00(1)$ & 1.000 \\
\hline Not practiced & 1.00 & & \\
\hline \multicolumn{4}{|l|}{ Denial } \\
\hline Practiced & $1.51(0.50,4.55)$ & $0.54(1)$ & 0.462 \\
\hline Not practiced & 1.00 & & \\
\hline \multicolumn{4}{|l|}{ Substance use } \\
\hline Practiced & $0.74(0.08,6.96)$ & $0.07(1)$ & 0.792 \\
\hline Not practiced & 1.00 & & \\
\hline \multicolumn{4}{|l|}{ Use of emotional } \\
\hline $\begin{array}{l}\text { support } \\
\text { Practiced }\end{array}$ & $\begin{array}{c}0.70(0.27,1.81) \\
1.00\end{array}$ & $0.54(1)$ & 0.461 \\
\hline \multicolumn{4}{|l|}{ Not practiced } \\
\hline \multicolumn{4}{|l|}{ Behavioral } \\
\hline Practiced & 1.00 & $0.05(1)$ & 0.821 \\
\hline \multicolumn{4}{|l|}{ Not practiced } \\
\hline \multicolumn{4}{|l|}{ Venting } \\
\hline $\begin{array}{l}\text { Practiced } \\
\text { Not practiced }\end{array}$ & $\begin{array}{c}2.00(0.78,5.11) \\
1.00\end{array}$ & $2.10(1)$ & 0.148 \\
\hline \multicolumn{4}{|l|}{ Use of instrumental } \\
\hline & $\begin{array}{c}1.14(0.42,3.13) \\
1.00\end{array}$ & $0.07(1)$ & 0.799 \\
\hline \multicolumn{4}{|l|}{ Not practiced } \\
\hline \multicolumn{4}{|l|}{ Positive reframing } \\
\hline Practiced & $0.62(0.23,1.69)$ & $0.88(1)$ & 0.618 \\
\hline \multirow{2}{*}{\multicolumn{4}{|c|}{ Self-blame }} \\
\hline & & & \\
\hline Practiced & $5.50(1.67,18.10)$ & $7.87(1)$ & 0.005 \\
\hline Not practiced & 1.00 & & \\
\hline \multicolumn{4}{|l|}{ Planning } \\
\hline Practiced & $0.93(0.32,2.72)$ & $0.019(1)$ & 0.890 \\
\hline Not practiced & 1.00 & & \\
\hline \multicolumn{4}{|l|}{ Humor } \\
\hline Practiced & $1.51(0.50,4.55)$ & $0.542(1)$ & 0.462 \\
\hline Not practiced & 1.00 & & \\
\hline \multicolumn{4}{|l|}{ Acceptance } \\
\hline Practiced & $1.10(0.32,3.77)$ & $0.024(1)$ & 0.877 \\
\hline \multirow{2}{*}{\multicolumn{4}{|c|}{ Religion }} \\
\hline & & & \\
\hline Practiced & $1.77(0.36,8.74)$ & $0.497(1)$ & 0.481 \\
\hline Not practiced & 1.00 & & \\
\hline
\end{tabular}

Table 5: Multivariable analysis of association between coping strategies and stress among respondents

\begin{tabular}{|c|c|c|c|c|}
\hline Variables & $\begin{array}{l}\text { Crude OR }{ }^{a} \\
(95 \% \mathrm{Cl})\end{array}$ & $\begin{array}{l}\text { Adjusted ORb } \\
\quad(95 \% \mathrm{Cl})\end{array}$ & $\begin{array}{c}\text { Wald } \\
\text { Statistics }^{b}(d f)\end{array}$ & $\begin{array}{c}P \\
\text { Value }^{\text {b }}\end{array}$ \\
\hline $\begin{array}{l}\text { Self-blame } \\
\text { Practiced } \\
\text { Not practiced }\end{array}$ & $5.50(1.67,18.10) 1.00$ & $\begin{array}{c}8.18(1.86,35.91) \\
1.00\end{array}$ & $7.75(1)$ & 0.005 \\
\hline
\end{tabular}


Among the stressors namely clinical, educational, financial and confidence stressors explored, the clinical stressors ranked highest followed by confidence stressor, educational and financial. This was similar as in the study among Macao nursing students except for the educational and financial stressors which just switched order in the Macao student nurses' study ${ }^{34}$. A study done among Ministry of Health Nursing students in another state in Malaysia, revealed clinical assignments and workload stressor as the commonest stressor (similar to another study), followed by clinical educator/instructor and ward staff stressor, clinical stressor, environment stressor, peer and nursing students from other colleges stressor, taking care of patients stressor and lastly lack of professional knowledge and skills stressor 37,38 . In a study in United States of America (USA), among junior degree nursing students, the most frequently perceived stressor was initial experiences - $34.5 \%$ (encompassed administrating injections, patient care, administering drugs and communicating with patient first time), followed by interpersonal relationships - $27.1 \%$ (problems interacting with instructors) and ability to perform roles $23.4 \%$ (stress in performing roles because of inadequate preparation and fear of failing ${ }^{39}$. Other studies have reported most common stressors as lack of professional knowledge and skills and stress from taking care of patient ${ }^{1,3,40}$. The reason nursing students in this study scored the clinical stressor as highest could be due to the professional clinical skills one has to learn in handling life and death situations which is inherently considered a known stressful environment where the fear of making mistakes and failing in examinations would be high. The confidence stressor was scored second highest as acquiring confidence depends on one's skill and knowledge, which has been scored as one of the stressors earlier. The financial stressor scored the lowest as all students are on student's loan from the government which reduces their stress in this area.

Confidence stressor was the only stressor significantly associated with stress in this study, similar to 2 other studies ${ }^{41,}{ }^{42}$. A study done in Turkey among year 2 nursing students reported 'lack of self-confidence in general' under the personal category of sources of stress examined ${ }^{43}$. Confidence is crucial for being able and sufficient in one's profession where an author has stated that students feel less confident before a patient, who has a lot of medical knowledge, which is a reality in today's world ${ }^{44}$

The top 3 ranked coping strategies practised by nursing students in this study were religion, acceptance and planning. Another study conducted in another northern state in Malaysia also reported similarly, religion as the first coping strategy and the third strategy as planning while the second coping strategy instrumental support differed from the current study which reported acceptance coping strategy ${ }^{38}$. In contrast, Taiwanese nursing students reported their coping strategies as seeking social support, problem solving and accepting responsibility ${ }^{45}$. The World Health organisation/European Haematology Association (WHO/EHA) guidelines stated that there are no standard guidelines for coping strategies but rather depend on cultural and socio-economic factors ${ }^{36}$. Several other studies have reported emotion focused coping strategies; positive appraisal and, seeking social support practices in Taiwan, Iran and USA $36,39,46$. The study in USA reported junior baccalaureate students utilised two problem-focused coping strategies; problem solving and seeking social support coping strategies-more frequently than two emotion-focused coping strategies-tension reduction and avoidance coping ${ }^{39}$. Malaysia being an Islamic country reported religion as the most frequent coping strategy, like Iran, another Islamic country, as religiosity was the most striking cultural feature for Islamic countries. In Australia, 3 problem-focused coping strategies (problem solving, recreational and sport and social support) and 1 emotion- focused (tension reduction) were practiced among the undergraduate nursing students ${ }^{33}$. In contrast Hong Kong nursing students practiced transference, staying optimistic, problem solving and avoidance as their coping strategies.

The only coping strategy associated with stress was self- blame in this study. Self- blame here is criticizing oneself and blaming oneself for things that happened. A study among Egyptian nursing students testing the association between coping strategies namely problem focused, seeking social support, detachment, wishful thinking, focusing on the positive, tension reduction, self-blame and keeping to oneself with stress only reported wishful thinking and tension reduction strategy associated with stress. A study among Medical and Health Sciences students in Malaysia recorded a significant association between self-blame coping strategy and stress as in the current study, in addition to acceptance and emotional support coping strategy ${ }^{47}$. In the current study, the practice of self-blame coping strategy could be explained by the young nursing students who have little awareness of existing coping strategies and may be inhibited in seeking support or help from instructors or supervisors.

\section{Limitations}

This is a cross-sectional study that prevents causal relationships to be established. This study is conducted only in one university, findings of which are not generalizable to other state universities or to the whole Malaysian nursing student population. This study did not have any Indian nursing students in the study (though Malaysia is multicultural), thus recommend future studies to be extended to other states to have a representative sample as the current study site 
was a Muslim majority state. The findings may be biased by students under-reporting and providing socially desirable answers, which need to be accepted with caution. None of the sociodemographic factors being significantly associated with stress could be due to a small sample size.

\section{CONCLUSIONS}

The prevalence of stress among the nursing students was $25 \%$. No sociodemographic factors were associated with stress. The highest mean stressor reported was clinical stressor. The only Stressor associated with stress was confidence stressor. The top 3 most frequently practiced coping strategies were religion, acceptance and planning. Self-blame was the only coping strategy associated with stress. $25 \%$ may be underreported figures. Since nursing students experience high stress levels due to clinical stressors, the faculty must address these stressors and bring awareness to nursing students to recognize and seek help. The instructors should be more supportive and introduce peer counselling sessions. It is timely that the faculty take big strides to enhance their interactions with students to improve student confidence and enable students to seek help and guide them with stress management workshops to evaluate their stress and coping strategies. This would allow students to strengthen their knowledge and assess their own stress levels and choose the ideal coping strategies, leading to a positive work environment with good learning experiences and improved academic performance. An evaluation of students' stress, coping and curriculum (theoretical and clinical) must be carried out among the students to identify the academic and clinical areas which need improvement.

\section{ACKNOWLEDGEMENT}

This study has gained approval from the Medical Research Ethics Committee UCSI University, Malaysia. (Reference number: FMS-024), and approval from the Dean of the University where the study was conducted. The authors would like to acknowledge the Head of the Nursing School who gave full cooperation in the conduct of the study and some of the medical students from UCSI University, who directly or indirectly were involved at different stages of the study.

\section{Conflicts of interest}

The authors declare no conflicts of interest

\section{REFERENCES}

1. Chan CK, So WK, Fong DY. Hong Kong baccalaureate nursing students' stress and their coping strategies in clinical practice. J Prof Nurs. 2009;25(5):30713.
2. Evans W, Kelly B. Pre-registration diploma student nurse stress and coping measures. Nurse Educ Today. 2004;24(6):473-82.

3. Sheu S, Lin H-S, Hwang S-L. Perceived stress and physio-psycho-social status of nursing students during their initial period of clinical practice: the effect of coping behaviors. Int J Nurs Stud. 2002;39(2):165-75.

4. Jonsén E, Melender H-L, Hilli Y. Finnish and Swedish nursing students' experiences of their first clinical practice placement-A qualitative study. Nurse Educ Today. 2013;33(3):297-302.

5. Admi H. Nursing students' stress during the initial clinical experience. J Nurs Educ. 1997;36(7):323-7.

6. Beck DL, Srivastava R. Perceived level and sources of stress in baccalaureate nursing students. $J$ Nurs Educ. 1991;30(3):127-33.

7. Junious DL, Malecha A, Tart K, Young A. Stress and perceived faculty support among foreign-born baccalaureate nursing students. J Nurs Educ. 2010;49(5):261-70.

8. Kang YS, Choi SY, Ryu E. The effectiveness of a stress coping program based on mindfulness meditation on the stress, anxiety, and depression experienced by nursing students in Korea. Nurse Educ Today. 2009;29(5):538-43.

9. Ratanasiripong $\mathrm{P}$, Ratanasiripong $\mathrm{N}$, Kathalae D. Biofeedback intervention for stress and anxiety among nursing students: a randomized controlled trial. ISRN Nurs. 2012;2012.

10. Tully A. Stress, sources of stress and ways of coping among psychiatric nursing students. J Psychiatr Ment Health Nurs. 2004;11(1):43-7.

11. Kumar R, Nancy O. Stress and coping strategies among nursing students. Nursing and Midwifery Research Journal. 2011;7(4):141-51.

12. Kurebayashi LFS, Do Prado JM, Da Silva MJP. Correlations between stress and anxiety levels in nursing students. $J$ Nurs Educ Pract. 2012;2(3):128.

13. Papazisis G, Tsiga E, Papanikolaou N, Vlasiadis I, Sapountzi-Krepia D. 
Psychological distress, anxiety and depression among nursing students in Greece. International Journal of Caring Sciences. 2008;1(1):42.

14. Pryjmachuk S, Richards DA. Predicting stress in pre-registration nursing students. $\mathrm{Br} J$ Health Psychol. 2007;12(1):125-44.

15. Sutherland VJ, Cooper CL. Understanding stress: A psychological perspective for health professionals: Chapman \& Hall/CRC; 1990.

16. Carver CS, Scheier MF. Situational coping and coping dispositions in a stressful transaction. J Pers Soc Psychol. 1994;66(1):184.

17. Lees $\mathrm{S}$, Ellis $\mathrm{N}$. The design of a stressmanagement programme for nursing personnel. J Adv Nurs. 1990;15(8):94661.

18. Adejumo $\mathrm{O}$, Brysiewicz P. Coping strategies adopted by baccalaureate nursing students in a problem-based learning programme. Educ Health. 1998;11(3):349.

19. Carver CS. You want to measure coping but your protocol'too long: Consider the brief cope. Int J Behav Med. 1997;4(1):92.

20. Deary IJ, Watson R, Hogston R. A longitudinal cohort study of burnout and attrition in nursing students. $J A d v$ Nurs. 2003;43(1):71-81.

21. Goldberg DP. User's guide to the General Health Questionnaire. Windsor. 1988.

22. Yusoff MSB, Rahim AFA, Jamil M. The sensitivity, specificity and reliability of the malay version 12-items general health (GHQ-12) in questionnaire detecting distressed medical students. ASEAN Journal of Psychiatry [Internet]. 2010. Available from:

http: / / www.aseanjournalofpsychiatry .org/oe11111.htm

23. Zulkefly SN, Baharudin R. Using the 12item General Health Questionnaire (GHQ-12) to assess the psychological health of Malaysian college students. Glob J Health Sci. 2010;2(1):73.

24. Yusoff MSB. The validity of the Malay Brief COPE in identifying coping strategies among adolescents in secondary school. Int Med J. 2011;18(1):29-33.

25. Wheeler HH. Nurse occupational stress research 4: the prevalence of stress. $\mathrm{Br}$ J Nurs. 1997;6(21):1256-60.

26. Caplan RP. Stress, anxiety, and depression in hospital consultants, general practitioners, and senior health service managers. BMJ. 1994;309(6964):1261-3.

27. Borrill C, Wall T, West M, Hardy G, Shapiro D, Carter A, et al. Mental health of the workforce in NHS trusts: Phase 1 final report. 1996.

28. Rimmer A. Staff stress levels reflect rising pressure on NHS, says NHS leaders. BMJ: British Medical Journal (Online). 2018;360.

29. Shamsuddin K, Fadzil F, Ismail WSW, Shah SA, Omar K, Muhammad NA, et al. Correlates of depression, anxiety and stress among Malaysian university students. Asian J Psychiatr. 2013;6(4):318-23.

30. Elias H, Ping WS, Abdullah MC. Stress and academic achievement among undergraduate students in Universiti Putra Malaysia. Procedia-Social and Behavioral Sciences. 2011;29:646-55.

31. Shaban IA, Khater WA, Akhu-Zaheya LM. Undergraduate nursing students' stress sources and coping behaviours during their initial period of clinical training: A Jordanian perspective. Nurse Educ Pract. 2012;12(4):204-9.

32. Moreira DP, Furegato ARF. Stress and depression among students of the last semester in two nursing courses. Rev Lat Am Enfermagem. 2013;21(SPE):155-62.

33. Lo R. A longitudinal study of perceived level of stress, coping and self-esteem of undergraduate nursing students: an Australian case study. J Adv Nurs. 2002;39(2):119-26.

34. Liu M, Gu K, Wong TK, Luo MZ, Chan MY. Perceived stress among Macao nursing students in the clinical learning environment. Int $J$ Nurs Sci. 2015;2(2):128-33.

35. Bam V, Oppong G, Ibitoye M. Stress and coping mechanisms of nursing students during clinical practice in Ghana. 
Journal of Science and Technology (Ghana). 2014;34(2):50-9.

36. Seyedfatemi N, Tafreshi M, Hagani $\mathrm{H}$. Experienced stressors and coping strategies among Iranian nursing students. BMC Nurs. 2007;6(1):11.

37. Shipton SP. The process of seeking stress-care: coping as experienced by senior baccalaureate nursing students in response to appraised clinical stress. J Nurs Educ. 2002;41(6):243-56.

38. Ab Latif R, Nor MZM. Stressors and coping strategies during clinical practices among diploma nursing students. Education in Medicine Journal. 2016;8(3).

39. Mahat G, editor Stress and coping: junior baccalaureate nursing students in clinical settings. Nursing forum; 1998: Wiley Online Library.

40. Ashmore R, Banks D. Self-disclosure in adult and mental health nursing students. Br J Nurs. 2002;11(3):172-7.

41. Goff A-M. Stressors, academic performance, and learned resourcefulness in baccalaureate nursing students. Int $J$ Nurs Educ Scholarsh. 2011;8(1).
42. Sharif F, Masoumi S. A qualitative study of nursing student experiences of clinical practice. BMC Nurs. 2005;4(1):6.

43. Oner Altiok H, Ustun B. The Stress Sources of Nursing Students. Educational Sciences: Theory and Practice. 2013;13(2):760-6.

44. Idczak SE. I am a nurse: nursing students learn the art and science of nursing. Nurs Educ Perspect. 2007;28(2):66-71.

45. Hsiao YC, Chien LY, Wu LY, Chiang CM, Huang SY. Spiritual health, clinical practice stress, depressive tendency and health-promoting behaviours among nursing students. J Adv Nurs. 2010;66(7):1612-22.

46. Tsai P-F. A middle-range theory of caregiver stress. Nurs Sci $Q$. 2003;16(2):137-45.

47. Al-Dubai SAR, Al-Naggar RA, AlShagga MA, Rampal KG. Stress and coping strategies of students in a medical faculty in Malaysia. Malays $J$ Med Sci. 2011;18(3):57. 